\title{
Cayratia emarginata (Vitaceae), a new species from Thailand and Vietnam
}

\author{
A. Trias-Blasi ${ }^{1 *}$, J.A.N. Parnell ${ }^{1}$, K. Chayamarit ${ }^{2}$, A. Teerawatananon ${ }^{3}$
}

Key words

\section{Cayratia}

new species

Thailand

Vietnam

Vitaceae
Abstract The new species Cayratia emarginata is validly published. A latin diagnosis, a full description and an illustration are provided. Diagnostic characters for this species are 3-foliolate leaves, farinose hairless petals and a cuspidate leaf apex.

Published on 9 February 2011

\section{INTRODUCTION}

De Loureiro (1790) published the genus Columella based on the type species Columella pedata Lour. Later, Columella was renamed Cayratia by De Jussieu (1818) so as to distinguish it from two other similarly named genera. Planchon (1887) treated Cayratia under Cissus L. sect. Cayratia while Gagnepain (1911) finally considered Cayratia and Cissus as separate genera.

Cayratia is a tropical and subtropical genus distributed in Asia, Africa, Australia and the Pacific Islands, comprising 63 species (Wen 2007). In Thailand it contains 6 species, none of them endemic.

During the preparation of the account of Thai Vitaceae for the Flora of Thailand the first author came across two specimens identified by the late Prof. Li as Cayratia emarginata; two additional specimens collected during a fieldtrip in 2007 were later identified as the same species. After much literature research and specimen examination, the first author realised that neither formal description of this species had been published, nor were the specimens conspecific with any other described species. Thus the first description and illustration of Cayratia emarginata is provided here.

Cayratia emarginata Trias-Blasi \& J.Parn., sp. nov. - Fig. 1

Species Cayratia trifolia (L.) Domin affinis, ab affinibus differt petala farinosus pilis omnio destituta et folia apice cuspidatus. - Typus: A.F.G. Kerr 10924 (holo P; iso BK, BM, K, L), Sam Roi Yawt [= Sam Roi Yot], Prachuap Khiri Khan Province, South-Western Region, Thailand, 7 Nov. 1926.

Herbaceous climber. Stem cylindrical, 1-3 mm diam, branched, hairy with soft villous hairs to $1 \mathrm{~mm}$ long, ridged; tendril 2-3-furcate, slender, wiry, leaf-opposed, cylindrical, peduncle straight, $1.5-4 \mathrm{~cm}$ by $0.5-1 \mathrm{~mm}$, then bifurcating and coiling for $2-7 \mathrm{~cm}$, hairy as stem. Leaves 3 -foliolate, alternate; petiole $1-3.5$ by

${ }^{1}$ Herbarium, Department of Botany, School of Natural Sciences, Trinity College Dublin, University of Dublin, Dublin 2, Ireland.

* Current address: Herbarium, Library, Art \& Archives, Royal Botanic Gardens, Kew, Richmond, Surrey, TW9 3AE, United Kingdom; corresponding author e-mail: triasbla@tcd.ie.

2 Queen Sirikit Botanic Garden, P.O. Box 7, Mae Rim, Chiang Mai 50180, Thailand.

3 Thailand Natural History Museum, National Science Museum, Technopolis, Pathum Thani 12120, Thailand. c. $1 \mathrm{~mm}$, hairy as stem, central petiolule $0.5-1.5 \mathrm{~cm}$ long, lateral petiolules $0.3-0.7 \mathrm{~mm}$ long, hairy as stem; central leaflet blade oval to ovate, $3-6$ by $1.5-3 \mathrm{~cm}$, base truncate to subauriculate; lateral leaflet blades semi-cordate, $3-5$ by $2-2.5 \mathrm{~cm}$, base oblique to cordate; margin deeply dentate with triangular teeth to 4 by $5 \mathrm{~mm}$, apex cuspidate; adaxial and abaxial sides hairy with appressed hairs to $1 \mathrm{~mm}$ long, veins protruding, 1 main basal vein, 6 pairs of secondary veins. Inflorescence ramified, axillary, mostly dividing dichotomously, corymbose, 1-2 cm long; peduncle $3.5-4 \mathrm{~cm}$ by c. $1 \mathrm{~mm}$, hairy as stem, pedicel $1.5-2 \mathrm{~mm}$ long, puberulent with hairs to $0.1 \mathrm{~mm}$ long. Buds globose to ovoid, $1.5-2$ by $1-1.5 \mathrm{~mm}$. Calyx cupuliform, entire, margin sinuate, c. 0.5 by $1.5 \mathrm{~mm}$, hairy as pedicel. Petals 4 , ovate, $2-2.3$ by $1-1.5 \mathrm{~mm}$, apex cucullate, farinose, hairless. Stamens 4; filaments flattened, broadening at the base, c. 1.3 $\mathrm{mm}$ long; anthers elliptic, medifixed, c. $0.8 \mathrm{~mm}$ long. Ovary adnate to the disc; disc with 4 distinct lobes, cupulate, 0.5-1 by c. $1.5 \mathrm{~mm}$, glabrous. Style conical, c. $0.8 \mathrm{~mm}$ long; stigma inconspicuous. Fruit unavailable.

Distribution - Thailand and Vietnam. A disjunct distribution, not yet collected in Cambodia, Laos and E/SE Thailand.

Habitat \& Ecology - Growing on limestone at $\leq 50 \mathrm{~m}$. Flowering in July.

Specimens examined. Thalland, Prachuap Khiri Khan, Sam Roi Yawt, 7 Nov. 1926, A.F.G. Kerr 10924 (BK, BM, K, L, P); Trang, Subdistrict Lampura, Tham i-so, 8 Apr. 2007, A. Trias Blasi 35 (BKF, TCD); Sa Kaeo, Khao Tangok. trail to the top, 24 Apr. 2007, A. Trias Blasi 52 (BKF, TCD). - VIETNAM, Cochinchine, mont Dinh, près de Ba Ria, Pierre $4353(\mathrm{P})$.

Notes - Cayratia emarginata is morphologically closest to C. trifolia. However, they can be easily distinguished because C. emarginata has farinose hairless petals and a cuspidate leaf apex, while $C$. trifolia has slightly to densely puberulent petals and an acute leaf apex.

Generally in Thai Cayratia the habit type seems to be correlated with seed morphology. Thus, species with herbaceous habit have seeds with an adaxial side with 2 faces and lack a deep cavity and occluding membrane, while species with a woody habit have seeds with their adaxial side possessing a cavity occluded by a membrane. Although no $C$. emarginata seeds have been seen, it is likely that if this character correlation is maintained, this species has seeds with an adaxial side with 2 faces and no cavity. 
Fig. 1 Cayratia emarginata Trias-Blasi \& J.Parn. a. Vegetative stem; b. flowering stem; c. flowers (all A.F.G. Kerr 10924 (P)). — Drawn by A. Teerawatananon.

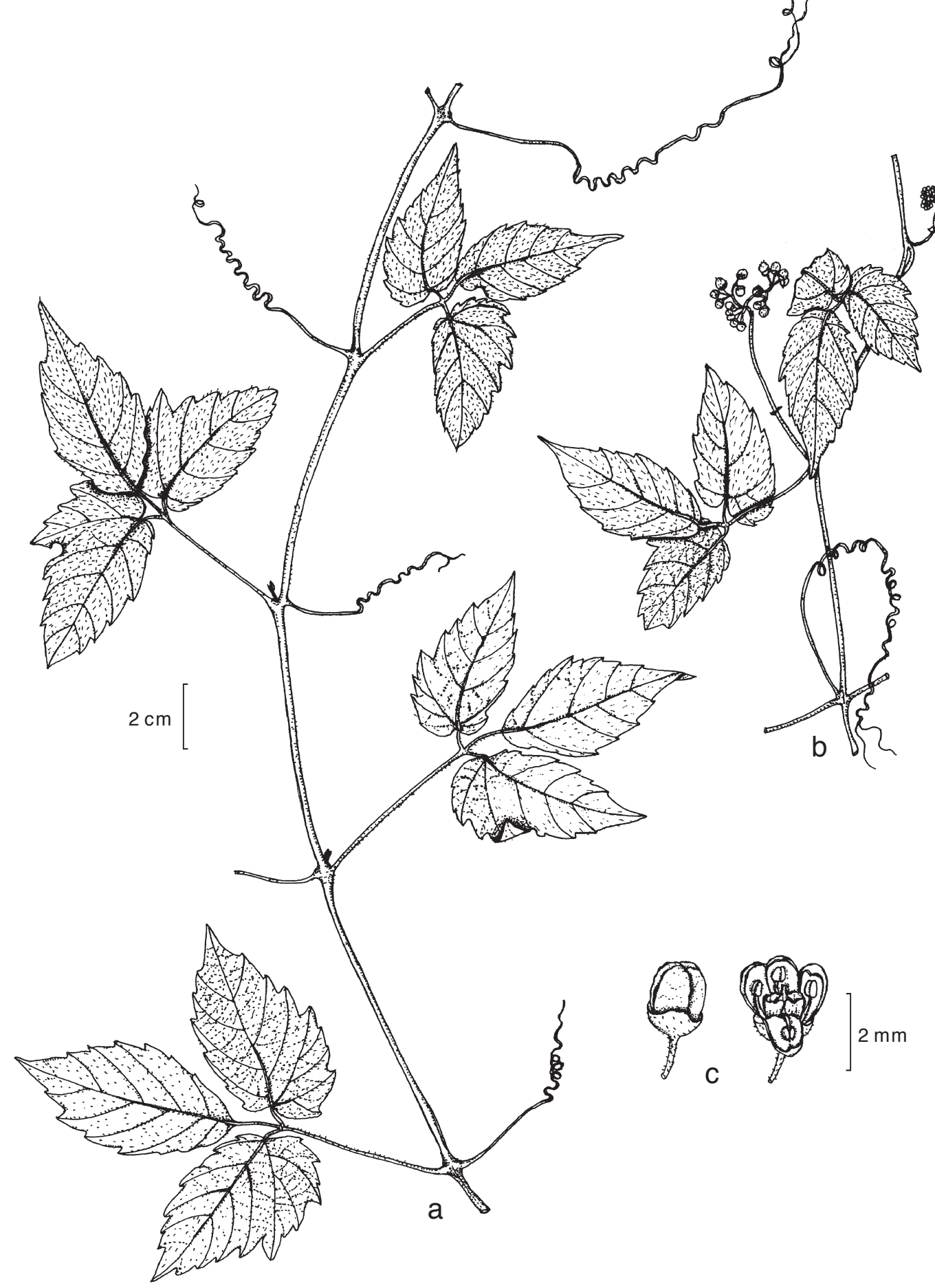

The specimen collected in the Sa Kaeo province, had a sticky secretion on the stems. In addition, all of the specimens examined grow in limestone terrain.

We have used as a holotype the duplicate of the specimen held in $\mathrm{P}$, because it contains flowers and is a good representative of the species. This specimen was previously identified as Cayratia mollissima. It can be easily differentiated from it because C. emarginata has a herbaceous habit and its leaves are generally much smaller ( $3-6$ by $1.5-3 \mathrm{~cm}$ ), while $C$. mollissima has a woody habit and bigger leaves $(7-20$ by $2.5-10 \mathrm{~cm})$.

Acknowledgements The authors thank the staff and students in TCD for their support. Thanks to the reviewers of this paper. The authors are also grateful to the curators and the staff of the following herbaria: BK, BKF, BM, $\mathrm{K}, \mathrm{L}, \mathrm{P}$ and TCD for the use or loan of specimens. The work was funded by a Trinity College Postgraduate Award, the Trinity College Postgraduate Travel
Fund, SYNTHESYS (European Union-funded Integrated Infrastructure Initiative grant), the Davis Expedition Fund, the IAPT Research Grants Program in Plant Systematics, the William Dickson Travelling Fund, BRT and Trinity College Dublin Botany Department.

\section{REFERENCES}

De Jussieu AL. 1818. Columella in Cuvier F. Dictionnaire des Sciences Naturelles 10: 103

De Loureiro J. 1790. Flora cochinchinensis. 1. Lisbon, Typis, et expensis academicis.

Gagnepain F. 1911. Un genre meconnu: classification des Cissus et Cayratia. Notulae Systematicae 1: 339-363.

Planchon JE. 1887. Monographie des Ampélidées vrais. In: De Candolle AFPP, De Candolle C (ed), Monographiae Phanaerogamarum 5: 305-654. Masson, Paris.

Wen J. 2007. Vitaceae. In: Kubitzki K (ed), The Families and Genera of Vascular Plants 9: 467-479. Springer-Verlag, Berlin. 